\title{
Internet method for the extraction of $N, N$-dimethyltryptamine from Mimosa hostilis roots: Does it really extract dimethyltryptamine?
}

\author{
GIORDANO NOVAK ROSSI ${ }^{1}$, EDUARDO JOSÉ CREVELIN ${ }^{2}$, GABRIELA DE OLIVEIRA SILVEIRA ${ }^{3}$, \\ MARIA EUGÊNIA COSTA QUEIROZ ${ }^{2,4,5}$, MAURICIO YONAMINE ${ }^{3}$, JAIME EDUARDO CECILIO HALLAK ${ }^{1,5}$ \\ and RAFAEL GUIMARÃES DOS SANTOS ${ }^{1,5,6 *}$
}

\author{
${ }^{1}$ Departamento de Neurociências e Ciências do Comportamento, Faculdade de Medicina de Ribeirão Preto, Universidade de São \\ Paulo, Ribeirão Preto, São Paulo, Brazil \\ ${ }^{2}$ Departamento de Química, Universidade de São Paulo, Ribeirão Preto, São Paulo, Brazil \\ ${ }^{3}$ Faculdade de Ciências Farmacêuticas, Universidade de São Paulo, Ribeirão Preto, São Paulo, Brazil \\ ${ }^{4}$ Faculdade de Ciências Farmacêuticas de Ribeirão Preto, Universidade de São Paulo, Ribeirão Preto, São Paulo, Brazil \\ ${ }^{5}$ National Institute of Science and Technology - Translational Medicine, Ribeirão Preto, São Paulo, Brazil \\ ${ }^{6}$ ICEERS Foundation (International Center for Ethnobotanical Education, Research and Services), Barcelona, Spain
}

(Received: January 9, 2019; accepted: February 22, 2019)

\begin{abstract}
Background and aims: The psychoactive capacity of the alkaloid $N, N$-dimethyltryptamine (DMT) has been known for decades, and its presence in beverages used in religious contexts around the world - such as ayahuasca - has attracted growing attention from the scientific community due to its possible anxiolytic and antidepressant effects. Mimosa hostilis, popularly known as jurema preta in Brazil, is a plant known to be utilized for extracting DMT, especially for recreational use. In this study, we confirmed if five different organic solvents ( $n$-hexane, ethyl acetate, $n$-butanol, dichloromethane, and chloroform) would extract non-purified DMT from M. hostilis and compared them in terms of DMT concentration found in the five organic solvents cited before. Methods: We have performed the straight to base technique for the extraction of DMT found on the Internet. The evaluation of DMT concentration in the organic solvents was performed via UPLC-ESI-MS/MS. No investigation was performed on other compounds in the solvents. Results: All the organic solvents extracted non-purified DMT, from lower to higher concentration: $n$-hexane, ethyl acetate, chloroform, $n$-butanol, and dichloromethane. Conclusions: The Internet straight to base method indeed extracts DMT from M. hostilis roots. However, DMT is not purified and the exact composition of the extracts and its toxicology is unknown. Thus, recreational DMT users are exposing themselves to products with unknown composition and effects.
\end{abstract}

Keywords: $N, N$-dimethyltryptamine, DMT, straight to base, extraction, Mimosa hostilis, jurema

\section{INTRODUCTION}

$N, N$-Dimethyltryptamine (DMT) is an indole alkaloid, which is naturally present in the human body as well as in a wide variety of other living organisms, including animals and plants (Barker, Mcilhenny, \& Strassman, 2012; Cameron \& Olson, 2018). Despite the fact that it was first isolated from botanic material in 1946, a decade would pass before the discovery of its hallucinogenic proprieties (De Lima, 1946; Szára, 1956).

DMT is the main psychoactive compound in ayahuasca and jurema [commonly known as vinho de jurema ("jurema wine")], two beverages traditionally used by South American indigenous groups for ritual and therapeutic purposes (De Lima, 1946; Gaujac, 2013). The most common source of DMT in ayahuasca is the leaves of Psychotria viridis, and in the case of jurema, it comes from Mimosa hostilis roots (commonly known as jurema preta)
(De Lima, 1946; Gaujac, 2013; Ott, 1994; Souza, Albuquerque, Monteiro, \& Amorim, 2008).

Ayahuasca is usually used in ritual or religious contexts, both in indigenous tribes and organized religious groups, such as Santo Daime and União do Vegetal, which are currently present in several countries (Gaujac, 2013; Labate, Rose, \& dos Santos, 2009). It is consumed for its therapeutic effects and self-knowledge (Labate et al., 2009; Ott 1994). In case of jurema, except for the traditional indigenous uses that are basically restricted to few parts of Brazil, particularly in the northeastern region, this plant is mostly used as a

\footnotetext{
* Corresponding author: Prof. Rafael Guimarães dos Santos, PhD Departamento de Neurociências e Ciências do Comportamento, Faculdade de Medicina de Ribeirão Preto, Universidade de São Paulo, Hospital das Clínicas, Terceiro Andar, Av. Bandeirantes, 3900, Ribeirão Preto, São Paulo, Brazil; Phone/Fax: +55 163602 2703; E-mail: banisteria@gmail.com
}

This is an open-access article distributed under the terms of the Creative Commons Attribution-NonCommercial 4.0 International License, which permits unrestricted use, distribution, and reproduction in any medium for non-commercial purposes, provided the original author and source are credited, a link to the CC License is provided, and changes - if any - are indicated. 
source of DMT to substitute $P$. viridis (where this plant is not easily available) for recreational use where it is usually smoked (Cakic, Potkonyak, \& Marshall 2010; Gaujac, 2013). In this context, DMT is extracted using home-made techniques, most notably a variation of the liquid-liquid extraction called "straight to base extraction" (STB). The extract is known to be smoked as obtained in doses of 2-60 $\mathrm{mg}$, producing an intense, short-lived (5-20 $\mathrm{min}$ ), psychedelic experience (Cakic et al., 2010; Dmt-Nexus, 2018; Riba, McIlhenny, Bouso, \& Barker, 2015).

The psychedelic properties of DMT are mediated by its agonist action on $5-\mathrm{HT}_{1 \mathrm{~A} / 2 \mathrm{~A} 2 \mathrm{C}}$ serotoninergic receptors expressed in cortical pyramidal neurons of brain regions involved in introspection and emotion processing, such as the default mode network (Palhano-Fontes et al., 2015). A recent randomized controlled trial showed that a single ayahuasca dose induced fast and enduring antidepressive and anxiolytic effects in patients with treatment-resistant depression (Palhano-Fontes et al., 2018).

DMT can be isolated in the laboratory from root barks and inner barks of $M$. hostilis, applying the liquid-liquid technique using $n$-hexane as an organic solvent for the isolation of the DMT-free base (Gaujac, 2013). However, the STB procedure found on the Internet (Dmt-Nexus, 2018) is widely available for users and it is not scientifically proven that it actually extracts DMT or if the effects are caused by other alkaloids that may be present on the plant and extracted during the procedure.

After considering that we did not find any reference in the scientific literature during our systematic search for DMT extractions regarding the STB procedure, we decided to do a preliminary investigation to discover if the method really extracts DMT. To do so, we utilized the "Lazyman's" extraction method found in the Dmt-Nexus site as a basis of our method, using five different organic solvents during the procedure ( $n$-hexane, ethyl acetate, $n$-butanol, dichloromethane, and chloroform) and comparing the results via liquid chromatography-tandem mass spectrometry analysis in order to obtain the DMT concentration of each solvent.

\section{SYSTEMATIC SEARCH FOR PREVIOUS DMT EXTRACTION TECHNIQUES}

To investigate if the STB extraction technique had been previously made and different solvents were previously used to extract DMT from M. hostilis, a systematic search was made in the PubMed database until October 18, 2018. The following search terms were selected: (dimethyltryptamine OR M. hostilis OR Mimosa tenuiflora OR jurema) AND (extraction OR extraction method OR solvents). Thirty-eight results were found, but none of them referred to DMT extraction (most references were related to the quantification of DMT in plant material or human matrices). However, after handsearching the citations in one of these references (Gaujac, Aquino, Navickiene, \& De Andrade, 2011), a procedure specifically for the DMT extraction was found (Gaujac, 2013).

In an attempt to expand these results, another search with less selective terms was performed: (M. hostilis OR dimethyltryptamine) AND (extraction). Twenty-one studies were found, but no new reference was selected. Due to the lack of available sources, further research was conducted through the references of the selected text (Gaujac et al., 2011) and in the doctoral thesis of the same author (Gaujac, 2013). During this handsearch, three other studies were found: De Lima (1946); Meckes-Lozoya et al. (1990); and Nicasio, Villarreal, Gillet, Bensaddek, and Fliniaux (2005). Therefore, four references were found in the systematic search for extractions of DMT from $M$. hostilis. The main scientific information related to DMT extraction from each citation is described in Table 1.

\section{MATERIALS AND METHODS}

\section{Materials}

\section{M. hostilis}

Barks and inner barks from $M$. hostilis roots were purchased on the Internet in a common marketplace website (www. mercadolivre.com.br). Due to the plants endemicity in Brazil's northeastern region and the fact that it is not scheduled by the government regarding its cultivation, use, and distribution, $M$. hostilis roots are easy to find and can be promptly acquired in Brazil.

\section{Chemical reagents and solvents}

$n$-Hexane, ethyl acetate, $n$-butanol, dichloromethane, chloroform, anhydrous ethanol, sodium sulfate, sodium chloride, hydrochloric acid, sodium hydroxide, and ammonium hydroxide were all acquired from Exodus brand, all being laboratory grade. Methanol for resuspension of high performance liquid chromatography grade was acquired from Merck (São Paulo, Brazil).

\section{Methods}

The "Lazyman's Straight To Base" extraction technique found on the Internet was used as basis for the procedure (Dmt-Nexus, 2018). To do so, $600 \mathrm{ml}$ of pure water was basified with slow addition of $60 \mathrm{~g}$ sodium hydroxide pellets. After cooling, this solution with $\mathrm{pH} 14$ was divided in equal volumes into five $500 \mathrm{ml}$ containers. To each of these containers were added $50 \mathrm{~g}$ of grinded M. hostilis roots, making up to $250 \mathrm{~g}$ of total botanic material, providing viscous dark brown solutions. After a week of daily agitation, $150 \mathrm{ml}$ of pure water was added to each container in order to dilute the solution and make it easier to work with. Afterward, $100 \mathrm{ml}$ of each solvent was added to each container, and after vigorously shaking, they were left sealed to rest at room temperature for another week. At the end of this period, the organic solvents were separated from the aqueous solution with a recovery rate varying from $80 \%$ to $95 \%$ volume utilized. All organic solvents were exposed to sodium sulfate to remove any water. A sample of $1 \mathrm{ml}$ of each solvent was poured into microfuge tubes, dried out, and stored at $-20{ }^{\circ} \mathrm{C}$ until analysis. All samples were discarded after the final analysis. 
Ultra performance liquid chromatography-electrospray ionization-tandem mass spectrometry (UPLC-ESI-MS/MS) analysis

Analyses were performed using a Waters UPLC Acquity System coupled to a Quattro Premier tandem MS with electrospray ionization (ESI) operated in the positive ion mode (Waters Corporation, Milford, MA, USA). Chromatographic separation was conducted on UPLC BEH C18 $2.1 \mathrm{~mm} \times 100 \mathrm{~mm}$, ID $1.7 \mu \mathrm{m}$ Acquity column using the following gradient elution: mobile phase A (2 mM ammonium formate buffer with $0.1 \%$ formic acid) and a mobile phase B $(0.1 \%$ formic acid in methanol $)$ at a constant flow rate of $0.3 \mathrm{ml} / \mathrm{min}$; A:B 90:10 (0 $\mathrm{min})-90: 10$ (0.1 $\mathrm{min})$ 50:50 (7 min)-50:50 (7.1 min)-90:10 (8 min). Samples were analyzed using a $5 \mu \mathrm{l}$ of injection volume. The tandem mass spectrometry analysis was performed using multiple reaction monitoring, the $\mathrm{m} / \mathrm{z}$ transitions were $188.9>57.8,116.7$, $143.8^{*}$ for DMT and $195.1>63.9,114.9,143.8^{*}$ for the internal standard DMT-d6. Transitions used for quantification are indicated with an asterisk.

\section{Sample preparation}

Sample preparation consisted in a fully validated dilution procedure using $2 \mathrm{mM}$ ammonium formate buffer with $0.1 \%$ formic acid (mobile phase A) to a final ratio of 1:20000. After dilution, $5 \mu \mathrm{l}$ of the diluted sample was injected in the UPLC-ESI-MS/MS system. DMT-d6 was added in all samples as internal standard.

\section{RESULTS}

All organic solvents were found to contain non-purified DMT. The concentration of DMT in each solvent was evaluated via UPLC-ESI-MS/MS analysis. The concentration results are shown in Table 2 and the analysis spectra for each solvent are provided in Figure 1.

\section{DISCUSSION}

We have concluded that the STB extraction found on the Internet extracts DMT from $M$. hostilis roots. In general terms, the extraction was simple to accomplish with very little to none emulsions observed and good organic solvents recoverability. In the Dmt-Nexus page used as guide for the

Table 2. Results of the UPLC-ESI-MS/MS analysis

\begin{tabular}{lcc}
\hline Sample & Organic solvent & DMT $(\mathrm{mg} / \mathrm{ml})$ \\
\hline 1 & $n$-Hexane & 0.22 \\
2 & Ethyl acetate & 1.28 \\
3 & Chloroform & 2.03 \\
4 & $n$-Butanol & 3.54 \\
5 & Dichloromethane & 3.73 \\
\hline
\end{tabular}

Note. DMT: $N, N$-dimethyltryptamine; UPLC-ESI-MS/MS: ultra performance liquid chromatography-electrospray ionizationtandem mass spectrometry. 
Rossi et al.

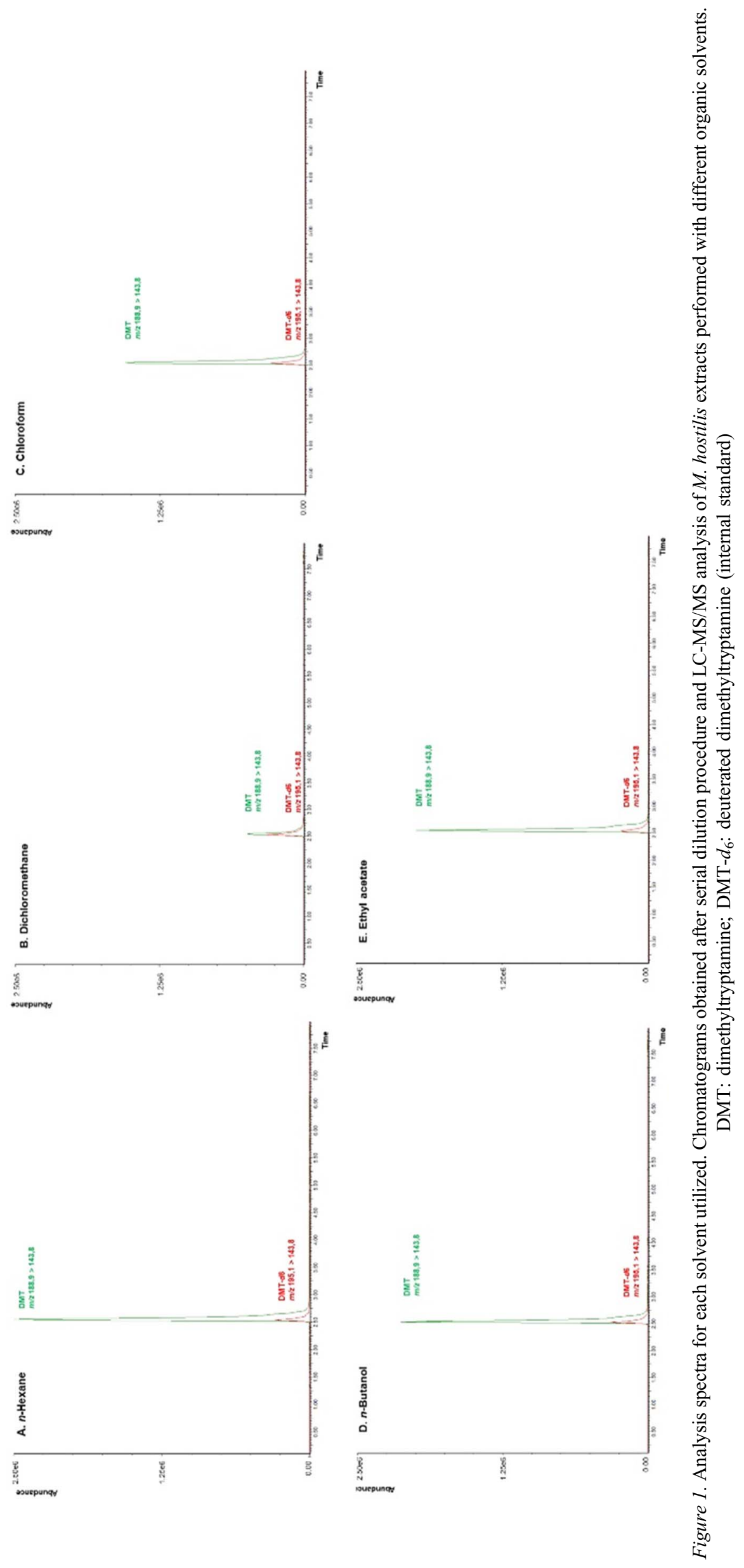


procedure, it is taken into account that longer exposure (i.e., several days) to the basified water provides higher yields with less manipulation of the extract. With this in view, we chose to let the extract sit for 2 weeks and extract it only once with the full organic solvents volume instead of extracting earlier with multiple small organic solvents volume. We have hypothesized that the presence of a high alkaline medium in direct contact to the botanic material for longer time breaks the cellulose bounds of the cellular walls from the roots and thus allows for more DMT to go into solution, providing higher yields at the end of the procedure. This was confirmed observing that the fibers that were not turned into fine dust after grinding were soft and malleable at the end of the extraction as they were discarded.

The fact that $n$-hexane has the lowest polarity of all organic solvents contributed to avoid the formation of emulsions when combined with aqueous phase and thus it was the highest volume of solvent separated in the final step of the extraction. On the other hand, its low polarity certainly accounts for the lowest DMT concentration found, as the DMT molecule possesses an amine group that conveys polarity to it.

Studies have shown that the solvent dichloromethane reacts with DMT to produce $N$-chloromethyl- $N, N$ dimethyltryptamine chloride (Brendt et al., 2008; Dunlap \& Olson, 2018). The biphasic state where dichloromethane and aqueous solution were in contact extended over a week. Considering these results, it is highly possible that some amount of DMT may have been lost to the aqueous phase during extraction, since the resultant reaction compound described has ionic nature. Taking this into account, it is surprising to see that dichloromethane was the solvent with highest DMT concentration. As our samples for analysis were dried and stored at $-20{ }^{\circ} \mathrm{C}$, we assume that this reaction did not take place after the extraction procedure ended.

In this study, we have utilized $n$-hexane as the most non-polar solvent because it was promptly available at our laboratory and had been used on the DMT extraction previously (Gaujac, 2013). However, considering its toxicity, further investigations should contemplate using of $N$-pentane or $N$-heptane as a substitute for $n$-hexane (Takeuchi, Ono, Hisanaga, Kitoh, \& Sugiura, 1980).

Finally, the major limitation of this work is the lack of purity assays of the extracts, due to law restrictions in Brazil regarding the possession of isolated/purified DMT. Despite this, the color of all organic solvents changed from light to dark yellowish or brownish, indicating the possible presence of substances other than DMT. On the other hand, amorphous DMT is more likely to account for the yellowish tint observed (Gaujac, 2013), particularly in the dichloromethane and the chloroform extracts where this color was noticed. $n$-Hexane was an exception, presenting no perceptual change in color. However, this is not conclusive evidence, and further studies on extract purity are needed in order to confirm the hypothesis that the $n$-hexane extract had higher degree of purity in regard to its DMT content. Finally, we also did not perform analysis of other possible toxic compounds potentially present in the solvents. Recreational users of these non-purified, home-made extracts of
DMT from $M$. hostilis could be potentially exposing themselves to chemical products with unknown toxicology or pharmacology. Further analytical and pharmacological studies of these products should be performed.

Acknowledgements: GNR received funding from CAPES (Coordenação de Aperfeicoamento de Pessoal de Nível Superior). RGdS is a Fellow of the Programa Nacional de Pós-Doutorado, Brazil (PNPD/CAPES). JECH received a CNPq (Brazil) Productivity Fellowship Award. Sponsors had no role in study design, data analysis, data interpretation, or writing of the report.

All authors had full access to all the data and had final responsibility for the decision to submit for publication. None of the authors received any specific funding for participating in this investigation.

Conflict of interest: The authors have no conflict of interests to disclose.

\section{REFERENCES}

Barker, S. A., Mcilhenny, E. H., \& Strassman, R. (2012). A critical review of reports of endogenous psychedelic $N$, $N$-dimethyltryptamines in humans: 1955-2010. Drug Testing and Analysis, 4(7-8), 617-635. doi:10.1002/dta.422

Brendt, S. D., Martins, C. P., Freeman, S., Dempster, N., Wainwright, M., Riby, P. G., \& Alder, J. F. (2008). $\mathrm{N}, \mathrm{N}$-Dimethyltryptamine and dichloromethane: Rearrangement of quaternary ammonium salt product during GC-EI and CI-MS-MS analysis. Journal of Pharmacological and Biomedical Analysis, 47(1), 207-212. doi:10.1016/ j.jpba.2007.12.024

Cakic, V., Potkonyak, J., \& Marshall, A. (2010). Dimethyltryptamine (DMT): Subjective effects and patterns of use among Australian recreational users. Drug Alcohol Dependence, 111(1-2), 30-37. doi:10.1016/j.drugalcdep.2010.03.015

Cameron, L. P., \& Olson, D. E. (2018). Dark classics in chemical neuroscience: $N, N$-Dimethyltryptamine (DMT). ACS Chemical Neuroscience, 9(10), 2344-2357. doi:10.1021/acschemneuro. $8 \mathrm{~b} 00101$

De Lima, O. G. (1946). Observações sobre o "vinho da Jurema" utilizado pelos índios Pancarú de Tacaratú (Pernambuco): Investigações complementares entre os Fulniô de Águas Belas (Pernambuco) e os remanescentes Tupís da Baía da Traição (Paraíba) [Observations on the "Jurema wine" used by the Pancarú Indians of Tacaratú (Pernambuco): Complementary investigations among the Fulniô of Águas Belas (Pernambuco) and the remaining Tupís da Baía da Traição (Paraíba)]. Arquivos do Instituto de Pesquisas Agronômicas, 4, 45-80.

Dmt-Nexus. (2018). Lazyman's tek. Retrieved from https://wiki. dmt-nexus.me/Lazyman's_tek. Accessed on: July 20, 2018.

Dunlap, L. E., \& Olson, D. E. (2018). Reaction of $N, N$ dimethyltryptamine with dichloromethane under common experimental conditions. American Chemical Society Omega, 3(5), 4968-4973. doi:10.1021/acsomega.8b00507

Gaujac, A. (2013). Estudos sobre o psicoativo N, N-dimetiltriptamina (DMT) em Mimosa hostilis (Willd.) Poiret e em bebidas 
consumidas em contexto religioso [Studies on the psychoactive $\mathrm{N}, \mathrm{N}$-dimethyltryptamine (DMT) in Mimosa hostilis (Willd.) Poiret and in drinks consumed in the religious context] (PhD dissertation). Universidade Federal da Bahia, Brazil.

Gaujac, A., Aquino, A., Navickiene, S., \& De Andrade, J. B. (2011). Determination of $N, N$-dimethyltryptamine in Mimosa tenuiflora inner barks by matrix solid-phase dispersion procedure and GC-MS. Journal of Chromatography B, Analytical Technologies in the Biomedical and Life Sciences, 107(10), 881-882. doi:10.1016/j.jchromb.2011.11.014

Labate, B. C., Rose, L. S., \& dos Santos, R. G. (2009). Ayahuasca religions: A comprehensive bibliography and critical essays (1st ed.). Santa Cruz, CA: Multidisciplinary Association for Psychedelic Studies (MAPS).

Meckes-Lozoya, M., Lozoya, X., Marles, R. J., Soucy-Breau, C., Sen, A., \& Arnason, J. T. (1990). N, N-dimethyltryptamine alkaloid in Mimosa tenuiflora bark (tepescohuite). Archivos de Investigación Médica (Mex), 21(2), 175-177.

Nicasio, M. P., Villarreal, M. L., Gillet, F., Bensaddek, L., \& Fliniaux, M. A. (2005). Variation in the accumulation levels of $\mathrm{N}, \mathrm{N}$-dimethyltryptamine in micropropagated trees and in in vitro cultures of Mimosa tenuiflora. Natural Product Research, 19(1), 61-67. doi:10.1080/14786410410001658860

Ott, J. (1994). Ayahuasca analogues: Pangean entheogens (1st ed.). Kennewick, WA: Natural Books Co.

Palhano-Fontes, F., Andrade, K. C., Tofoli, L. F., Santos, A. C., Crippa, J. A., Hallak, J. E., Ribeiro, S., \& Araujo, D. B. (2015). The psychedelic state induced by ayahuasca modulates the activity and connectivity of the default mode network. PLoS One, 10(2), e0118143. doi:10.1371/journal.pone.0118143

Palhano-Fontes, F., Barreto, D., Onias, H., Andrade, K. C., Novaes, M. M., Pessoa, J. A., Mota-Rolim, S. A., Osório, F. L., Sanches, R., Dos Santos, R. G., Tófoli, L. F., de Oliveira Silveira, G., Yonamine, M., Riba, J., Santos, F. R., SilvaJunior, A. A., Alchieri, J. C., Galvão-Coelho, N. L., LobãoSoares, B., Hallak, J. E. C., Arcoverde, E., Maia-de-Oliveira, J. P., \& Araújo, D. B. (2018). Rapid antidepressant effects of the psychedelic ayahuasca in treatment-resistant depression: A randomized placebo-controlled trial. Psychological Medicine, 49(4), 655-663. doi:10.1017/S0033291718001356.

Riba, J., McIlhenny, E. H., Bouso, J. C., \& Barker, S. A. (2015). Metabolism and urinary disposition of $N, N$-dimethyltryptamine after oral and smoked administration: A comparative study. Drug Test and Analysis, 7(5), 401-406. doi:10.1002/ dta. 1685.

Souza, R. S. O., Albuquerque, U. P., Monteiro, J. M., \& Amorim, E. L. C. (2008). Jurema-Preta (Mimosa hostilis [Willd.] Poir.): A review of its traditional use, phytochemistry and pharmacology. Brazilian Archives of Biology and Technology, 51(5), 937-947. doi:10.1590/s1516-89132008000500010.

Szára, S. (1956). Dimethyltryptamine: Its metabolism in man; the relation to its psychotic effect to the serotonin metabolism. Experientia, 12(11), 441-442. doi:10.1007/BF02157378.

Takeuchi, Y., Ono, Y., Hisanaga, N., Kitoh, J., \& Sugiura, Y. (1980). A comparative study on the neurotoxicity of $n$-pentane, $n$-hexane, and $n$-heptane in the rat. British Journal of Industrial Medicine, 37(3), 241-247. 